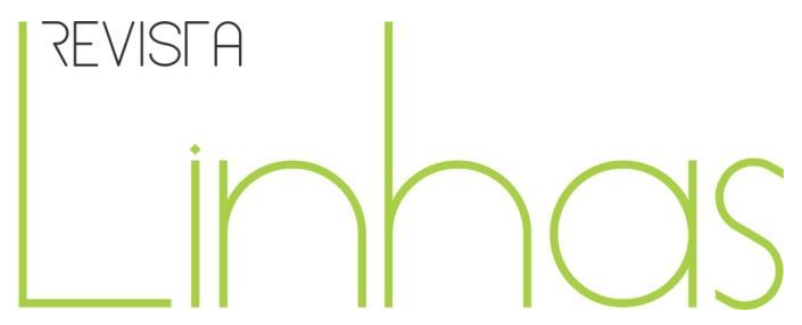

\title{
Educação de qualidade e responsabilidade social universitária: uma relação indissociável
}

\section{Resumo}

O presente artigo teve a pretensão de discutir a relação indissociável entre a qualidade da educação, em especial a do Ensino Superior, aferida pelo Sistema Nacional de Avaliação da Educação Superior (SINAES), e a responsabilidade social. Para tal feito, utilizou-se, um recorte do Eixo 2 desse Sistema, denominado Desenvolvimento Institucional. Nesse Eixo, são avaliadas duas dimensões das Instituições de Educação Superior (IES): a Missão e o Plano de Desenvolvimento Institucional (PDI) e a responsabilidade social universitária. Utilizou-se como método a pesquisa descritiva e a análise documental, que verificou os documentos SINAES e o Plano de Desenvolvimento da Educação (PDE). Os resultados apontam que a educação de qualidade e a responsabilidade social ganharam espaço nas Instituições de Educação Superior em função dos reflexos do mundo globalizado e das demandas por uma educação que efetivamente contribua para o desenvolvimento social e cidadão que emerge em uma nação. As dimensões avaliativas do SINAES acenam para uma ação integral entre ensino, pesquisa e extensão, fato que sinaliza claramente a emergência da prática da indissociabilidade, fato que viabiliza e, em certa medida, concretiza este ideário de compromisso social para as IES. Ficou evidente que a responsabilidade social começou a se expandir no espaço acadêmico por meio de pesquisas, publicações, seminários e congressos, elementos que carregam consigo os princípios e preocupação da educação de qualidade, visto sua abrangência e benefícios relacionados às boas práticas acadêmicas.

Palavras-chave: Ensino Superior. Qualidade. Responsabilidade Social Universitária.

\section{Para citar este artigo:}

DE MARCO, Ricardo Antonio; SARMENTO, Dirleia Fanfa. Educação de qualidade e responsabilidade social universitária: uma relação indissociável. Revista Linhas. Florianópolis, v. 20, n. 43, p. 234-255, maio/ago. 2019 .

\section{Ricardo Antonio De Marco}

Universidade La Salle - Unilasalle Canoas/RS

ricardo.antonio.demarco@gmail.com

Dirleia Fanfa Sarmento

Universidade La Salle - Unilasalle Canoas/RS

dirleia.sarmento@unilasalle.edu.br 


\title{
Quality education and university social responsibility: an indysociated relationship
}

\begin{abstract}
This article aimed to discuss the inseparable relationship between the quality of education, especially that of Higher Education, as measured by the National System for the Evaluation of Higher Education (SINAES), and social responsibility. For this purpose, a cut of Axis 2 of this System, called Institutional Development, was used. In this Hub, two dimensions of Higher Education Institutions (HEIs) are evaluated: the Mission and the Institutional Development Plan (PDI) and university social responsibility. Descriptive research and documentary analysis were used as a method, which verified the SINAES documents and the Education Development Plan (PDE). The results point out that quality education and social responsibility have gained space in Higher Education Institutions due to the reflections of the globalized world and the demands for an education that effectively contributes to the social and citizen development that emerges in a nation. The evaluation dimensions of the SINAES signal an integral action between teaching, research and extension, a fact that clearly signals the emergence of the practice of inseparability, a fact that makes feasible and, to a certain extent, concretizes this ideology of social commitment for HEls. It became clear that social responsibility began to expand in academic space through research, publications, seminars and congresses, elements that carry with them the principles and concern of quality education, given its breadth and benefits related to good academic practices.
\end{abstract}

Keywords: Higher education. Quality. University Social Responsibility. 


\section{Introdução}

As questões ligadas à qualidade trazem elementos que geram inúmeros debates na academia e na idealização da educação como bem social que possa atender de forma abrangente os anseios de formação cidadã de uma população, em especial no Brasil. Segundo o Instituto Nacional de Estudos e Pesquisas Educacionais Anísio Teixeira (BRASIL, 2004, p. 3):

Os conceitos, as concepções e as representações sobre o que vem a ser uma Educação de Qualidade alteram-se no tempo e espaço, especialmente se considerarmos as transformações mais prementes da sociedade contemporânea, dado as novas demandas e exigências sociais decorrentes das alterações que embasam a reestruturação produtiva em curso $[\ldots]$.

Nesse âmbito, o Brasil (2004) destaca que em vista das múltiplas significações atribuídas à qualidade da educação, perpassam inúmeros fatores que alimentam esse olhar, que estão relacionados à avaliação, natureza, propriedades e aos fatores desejáveis ao processo educativo, orientando a produção, organização, gestão e disseminação de saberes e conhecimentos fundamentais ao exercício da cidadania.

Complementarmente, o mesmo Instituto assevera que a qualidade da educação é um fenômeno complexo, de conceito polissêmico e que deve ser abordado por dimensões comuns. Prevista pela UNESCO (2003) como o que concerne à relação de insumos, processos e resultados, pontualmente, essa correlação atribuída à qualidade da educação envolve a relação entre os recursos materiais e humanos. Além disso, qualidade se constrói a partir da relação que ocorre na escola e na sala de aula, ou seja, a partir dos processos de ensino e aprendizagem, os currículos, as expectativas de êxito com relação à aprendizagem das crianças e a partir dos resultados educativos, representados pelo desempenho do aluno.

No que tange à qualidade na educação de ensino superior, a abordagem mais presente está contida no Plano de Desenvolvimento da Educação (BRASIL, 2007), que enfatiza o papel das Instituições de Educação Superior (IES) para o desenvolvimento sociocultural, econômico e científico do país. Estabelece como diretriz "a expansão da 
Educação Superior com qualidade". A métrica de acompanhamento de qualidade educacional nas IES é o Sistema Nacional de Avaliação da Educação Superior (BRASIL, 2004).

A partir das concepções de qualidade previstas no SINAES, ganha contornos de extrema importância a responsabilidade social, que foi somada a um conjunto de indicadores avaliativos atinentes a uma educação de qualidade no Ensino Superior, tornando-se uma exigência para qualquer IES, seja ela pública ou privada (ASHLEY, FERREIRA, REIS, 2006).

O tema responsabilidade social encontra-se em emergência no âmbito das políticas educacionais, entretanto, há pouca clareza sobre o assunto, particularmente na sociedade em geral. Nesse contexto, se destaca a ampliação do conceito e preocupação social das ações da gestão de uma instituição de ensino, particularmente, de Ensino Superior, no que concerne ao impacto social das decisões emanadas e irradiadas pelas instituições, sejam elas públicas ou privadas.

O anseio de consolidar um sentido de responsabilidade social na educação, especialmente no Ensino Superior, aproxima-se dos preceitos iniciais sobre o tema. Segundo Alessio (2008), o marco de responsabilidade social nas empresas ocorreu nos Estados Unidos da América, nos anos de 1960 do século passado, época em que outros países ainda não viviam com problemas de ordem social. Nesse norte, Pernalete e Ortega (2010) destacam que a responsabilidade social empresarial é o principal antecedente da responsabilidade social comumente disseminada nos diversos tipos de organizações e instituições.

Originalmente, o conceito de responsabilidade social foi delineado por Drucker (2009, p. 84):

Cada um é responsável pelo impacto que causa. [...] cedo ou tarde a sociedade vai considerar qualquer impacto causado um ataque à sua própria integridade e vai cobrar um alto preço daqueles que não tomaram para si a responsabilidade de trabalhar para eliminar o impacto ou para descobrir uma solução para o problema.

Nesta perspectiva, chama a atenção o pressuposto de que todas as decisões resultam em ações e, estas, por sua vez, sem exceção, impactam de alguma maneira na 
vida das pessoas, sejam elas do presente ou de gerações futuras. Agir de forma socialmente responsável implica em preocupar-se com a qualidade do impacto das ações sobre as pessoas e medir as consequências desse impacto. Portanto, é inegável a importância da responsabilidade social das organizações, entre elas as Instituições de Educação Superior.

Nessa perspectiva, conforme Drucker (2009, p. 83):

A responsabilidade social seja de uma empresa, de um hospital ou de uma universidade podem aparecer em duas áreas. Podem surgir dos impactos sociais causados pela instituição, ou surgir como problemas da própria sociedade. Ambas devem ser consideradas pela administração, porque a instituição que os administradores dirigem está necessariamente inserida na sociedade e na comunidade. Todavia, sob qualquer outro ponto de vista, as duas são diferentes. A segunda preocupa-se com o que uma instituição pode fazer em prol da sociedade.

Trata-se de uma abordagem da área administrativa que, evolutivamente, empresta sua essência para o ensino superior, conforme destaca Vallaeys (2006, p. 36):

[...] a responsabilidade social empresarial é um conjunto de práticas da organização que integra sua estratégia corporativa e que tem como finalidade evitar danos e/ou gerar benefícios para todas as partes envolvidas na atividade da empresa (clientes, empregados, acionistas, comunidade, periferia etc.), com finalidades racionais, que devem redundar em benefício tanto da organização como da sociedade.

Conforme essas abordagens, o conceito de responsabilidade social está associado à produção de bens e serviços úteis, fazendo uso, em seus processos, de conceitos morais da honestidade, integridade, justiça e confiança, que devem permear os princípios constitutivos e norteadores de uma instituição.

A responsabilidade social apresenta íntima relação com a estrutura institucional das universidades. Seu reconhecimento normalmente se apresenta na medida em que há clareza da atuação das IES no meio em que atuam, fato que deve acompanhar o processo 
de desenvolvimento da sociedade. Segundo Calderón (2006), a responsabilidade social está no "DNA" das IES, visto seu papel e função social diante do seu contexto.

Assim, percebe-se que a responsabilidade social deve partir do individual para o coletivo, isto é, a pessoa compromete-se individualmente e coletivamente com ações sociais, seja no ambiente de trabalho, na rua, em casa etc. A prática de responsabilidade social vai além da postura legal da empresa, pois significa uma mudança de atitude, numa perspectiva da qualidade das relações e da geração de valores para a sociedade. A responsabilidade social ajuda na construção de uma sociedade mais justa e melhor para todos, sendo uma temática transversal frequentemente estudada nas Ciências Econômicas e Ciências Políticas e Administrativas, portanto, é fato presente em instituições com e sem fins lucrativos, estendendo sua penetração e capilaridade nas organizações sociais, entre elas, as instituições de educação superior.

Nesse horizonte, a educação se consolida essencialmente como uma prática social presente em diferentes espaços e momentos da produção da vida social. Nesse contexto, particularmente, a qualidade do ensino superior é induzida por objetos e princípios préestabelecidos intrínsecos em políticas públicas que orientam o processo ensinoaprendizagem, pois cada país, com sua trajetória histórico-cultural e com o seu projeto de nação, estabelece diretrizes e bases para o seu sistema educacional (BRASIL, 2004).

Frente ao desafio de compreender as implicações da busca de uma educação de qualidade e da sua responsabilidade social, este texto se propõe a contribuir com reflexões sobre a qualidade da educação e a responsabilidade social como elemento indissociável para o ensino superior, levando em conta a riqueza e as especificidades de cada conceito, bem como apresentar indicações que subsidiem o debate sobre as concepções e os conceitos da qualidade da educação, especialmente da educação superior e a responsabilidade social universitária sob a vertente da indissociabilidade, sendo assim, necessária a descrição e estabelecimento de algumas dimensões que possam balizar a discussão dessa temática.

\footnotetext{
${ }^{1}$ Usamos a expressão DNA (Ácido Desoxirribonucleico - molécula presente no núcleo das células de todos os seres vivos e que carrega toda a informação genética de um organismo) no sentido figurado, significando aqui a responsabilidade social, que configuraria a constituição, o fim último e inegável das IES.
} 
Considerando o exposto, o texto em tela tem como centralidade a qualidade da educação, em especial a do Ensino Superior, aferida pelo Sistema Nacional de Avaliação da Educação Superior (SINAES), utilizando-se para tal feito, de um recorte do Eixo 2 deste Sistema, denominado Desenvolvimento Institucional. Nesse Eixo, são avaliadas duas dimensões das Instituições de Educação Superior (IES): a Missão e o Plano de Desenvolvimento Institucional (PDI); e a responsabilidade social da instituição. Trata-se, portanto, de uma contextualização analítico-discursiva.

A seguir, apresentamos aspectos gerais sobre qualidade no ensino, centrada no Ensino Superior, suportada pelo Sistema Nacional de Avaliação da Educação Superior (SINAES). Na sequência, discutimos a responsabilidade social universitária e suas interrelações com a qualidade do ensino demonstrada a partir dos preceitos de indissociabilidade. Por fim, são explicitadas algumas considerações finais sobre o tema em pauta.

\section{Sistema Nacional de Avaliação da Educação Superior (SINAES): um olhar sobre a qualidade no ensino superior}

É importante reconhecer que a qualidade da educação é um conceito normativo e multifatorial "porque em su definición intervienen, al menos, dimensiones correspondientes a la filosofia, la pedagogia, la cultura, la sociedad y la economia" (UNESCO, 2003, p. 44). Nessa ótica, a UNESCO acrescenta que, para chegar a termo, a qualidade deve interferir no meio educacional considerando no seu viés a relevância, a pertinência, a equidade, a eficiência e a eficácia do processo educacional.

Por outro olhar, Ferrer (1999) vê o conceito de qualidade na educação como sendo uma polissemia, indicando que o termo é composto de ambiguidades. Desse modo, Burlamaqui (2008, p. 135) destaca que essa terminologia aplicada à educação tem "significados diferentes para distintos observadores e grupos de interesse, de maneira que há percepções divergentes acerca do que deveria ser mudado, em termos de garantia da qualidade". Segundo esse autor, quando se fala de qualidade da educação, se está falando de uma realidade complexa, como um sistema, uma instituição ou curso. Complementarmente, Ferrer (1999) destaca que o reconhecimento da 
multifuncionalidade do conceito deve ser aplicado à educação, tendo em vista as várias dimensões que o contexto educacional, particularmente o ambiente universitário, apresenta como implicações para sua definição.

Para Burlamaqui (2008), o conceito de qualidade no Ensino Superior, além de ser complexo e multidimensional, está intrinsecamente relacionado à avaliação. Assim, a qualidade passa a ser o foco central dos sistemas de avaliação, visto que em grande medida os processos avaliativos visam, antes de quaisquer outros aspectos, conhecer a qualidade por meio de indicadores que se demonstrem capazes de uma aferição qualitativa da educação superior.

Nesse caminho, Cunha e Wertheim (2004) destacam o que trata a Declaração Mundial de Paris para a política do ensino superior brasileiro, reforçando que a qualidade da educação superior é um conceito multidimensional que permeia o ensino, a pesquisa, até as implicações científicas, os docentes, o estudante, a estrutura física, os equipamentos, os serviços de extensão à comunidade e, inclusive, o ambiente acadêmico em geral.

Nesse contexto, o Plano de Desenvolvimento da Educação (PDE) ${ }^{2}$ enaltece o papel das IES para o desenvolvimento sociocultural, econômico e científico do país, estabelecendo diretrizes para a uma expansão da educação superior com qualidade. $O$ (PDE) consignou no Brasil a forma de medição de qualidade da educação nas IES, que deve atender ao Sistema Nacional de Avaliação da Educação Superior (SINAES), o qual foi instituído pela Lei $\mathrm{n}^{\circ}$ 10.861, de 14 de abril de 2004. Esse Sistema tem a "missão de avaliar a graduação valorizando aspectos indutores da melhoria da qualidade da educação superior e da formação acadêmica dos estudantes brasileiros” (BRASIL, 2015, p. 21). O objetivo do SINAES é "assegurar processo nacional de avaliação das instituições de educação superior, dos cursos de graduação e do desempenho acadêmico de seus estudantes" (BRASIL, Art. $1^{\circ}$ ) e tem por finalidade:

\footnotetext{
${ }^{2}$ Apresentado ao país em 15 de março de 2007, o Plano de Desenvolvimento da Educação (PDE) foi lançado oficialmente em 24 de abril, simultaneamente à promulgação do Decreto $n^{\circ} 6.094$, dispondo sobre o "Plano de Metas Compromisso Todos pela Educação".
} 
[...] a melhoria da qualidade da educação superior, a orientação da expansão da sua oferta, o aumento permanente da sua eficácia institucional e efetividade acadêmica e social e, especialmente, a promoção do aprofundamento dos compromissos e responsabilidades sociais das instituições de educação superior, por meio da valorização de sua missão pública, da promoção dos valores democráticos, do respeito à diferença e à diversidade, da afirmação da autonomia e da identidade institucional. (BRASIL, 2004, $\S 1^{\circ}$ )

O Sistema Nacional de Avaliação da Educação Superior (SINAES) é formado por três componentes principais: a avaliação das instituições, avaliação dos cursos e avaliação do desempenho dos estudantes. O SINAES avalia todos os aspectos que giram em torno desses três eixos estendidos em: ensino, pesquisa, extensão, responsabilidade social, desempenho dos alunos, gestão da instituição, corpo docente, instalações e vários outros aspectos (INEP, 2015).

O SINAES possui uma série de instrumentos complementares: autoavaliação, avaliação externa, Exame Nacional de Desempenho de Estudantes (ENADE), avaliação dos cursos de graduação e instrumentos de informação (censo e cadastro). Segundo o INEP (2015), os processos avaliativos são coordenados e supervisionados pela Comissão Nacional de Avaliação da Educação Superior (CONAES). A operacionalização é de responsabilidade do INEP.

A eficácia institucional e a efetividade acadêmica e social das IES são obtidas a partir das avaliações sistemáticas que o SINAES operacionaliza. Assim, segundo INEP (2015), os órgãos governamentais utilizam-se dos resultados dessas avaliações para orientar políticas públicas e; pelos estudantes, pais de alunos, instituições acadêmicas e público em geral, para orientar suas decisões quanto à realidade dos cursos e das instituições.

O conjunto de dimensões avaliativas do SINAES está organizado em cinco eixos e suas respectivas dimensões de avaliação, conforme indicado no quadro 1. 
Quadro 1: Eixos e dimensões avaliativas do SINAES

\begin{tabular}{|l|l|}
\hline \multicolumn{1}{|c|}{ Eixos } & \multicolumn{1}{|c|}{ Dimensões } \\
\hline $\begin{array}{l}\text { Eixo 1: Planejamento e } \\
\text { Avaliação Institucional }\end{array}$ & Dimensão 8: Planejamento e Avaliação. \\
\hline $\begin{array}{l}\text { Eixo 2: Desenvolvimento } \\
\text { Institucional }\end{array}$ & $\begin{array}{l}\text { Dimensão 1: Missão e Plano de Desenvolvimento Institucional. } \\
\text { Dimensão 3: Responsabilidade Social da Instituição. }\end{array}$ \\
\hline Eixo 3: Políticas Acadêmicas & $\begin{array}{l}\text { Dimensão 2: Políticas para o Ensino, a Pesquisa e a Extensão. } \\
\text { Dimensão 4: Comunicação com a Sociedade. } \\
\text { Dimensão 9: Política de Atendimento aos Discentes. }\end{array}$ \\
\hline Eixo 4: Políticas de Gestão & $\begin{array}{l}\text { Dimensão 5: Políticas de Pessoal. } \\
\text { Dimensão 6: Organização e Gestão da Instituição. } \\
\text { Dimensão 10: Sustentabilidade Financeira. }\end{array}$ \\
\hline Eixo 5: Infraestrutura Física & Dimensão 7: Infraestrutura Física. \\
\hline
\end{tabular}

Fonte: Elaborado a partir da Nota Técnica n 14/2014 - CGACGIES/DAES/INEP/MEC.

O foco de análise deste texto centra atenção no Eixo 2, Desenvolvimento Institucional. Nele, são avaliadas as Dimensões 1 e 3: Missão e o Plano de Desenvolvimento Institucional (PDI) e a Responsabilidade Social da Instituição, respectivamente, contemplando os seguintes aspectos: missão institucional, metas e objetivos do PDI; coerência entre o PDI e as atividades de ensino de graduação e de pósgraduação; coerência entre o PDI e as práticas de extensão; coerência entre o PDI e as atividades de pesquisa/iniciação científica, tecnológica, artística e cultural; coerência entre o PDI e as ações institucionais no que se refere à diversidade, ao meio ambiente, à memória cultural, à produção artística e ao patrimônio cultural; coerência entre o PDI e as ações institucionais voltadas para o desenvolvimento econômico e social; coerência entre o PDI e ações de responsabilidade social: inclusão social; coerência entre o PDI e ações afirmativas de defesa, e promoção dos direitos humanos e igualdade étnico-racial; internacionalização: coerência entre o PDI e as ações institucionais. 


\section{Responsabilidade social universitária: processo em evolução}

Com o SINAES, a responsabilidade social passou a fazer parte do conjunto de indicadores avaliativos atinentes a uma educação de qualidade no ensino superior, tornando-se uma exigência para qualquer IES, seja ela pública ou privada (ASHLEY, FERREIRA, REIS, 2006). Dessa forma, para Vallayes (2006, p. 39):

A Responsabilidade Social Universitária exige, a partir de uma visão holística, a articulação dos diversos setores da instituição, em um projeto de promoção social de princípios éticos e de desenvolvimento social equitativo e sustentável, com vistas à produção e transmissão de saberes responsável e à formação de profissionais cidadãos igualmente responsáveis.

A responsabilidade social, particularmente no final do século passado e início deste novo milênio, se apresenta como um tema cada vez mais significativo para o comportamento das organizações, exercendo impactos nos objetivos, nas estratégias e na própria missão da organização social.

Trata-se de um fenômeno organizacional e institucional relativamente novo, advindo possivelmente da globalização da economia e suas implicações de corresponsabilidade de efeitos produtivos e de mercado. Nesse horizonte, as organizações centraram seu direcionamento para o produto, para o mercado e para o cliente, sem levar em consideração os efeitos das transações contidas nas atividades. Assim, percebia-se que o movimento predominante era de empresas voltadas para o social, no Brasil e em outros países da América Latina. Embora possam existir exceções, as empresas procuram converter os obstáculos sociais em oportunidades de negócios, usando isso como estratégia de marketing e como incremento de consumo.

A responsabilidade social universitária, segundo Vallayes (2006, p. 39):

[...] exige, a partir de uma visão holística, a articulação dos diversos setores da instituição, em um projeto de promoção social de princípios éticos e de desenvolvimento social equitativo e sustentável, com vistas à produção e transmissão responsáveis de saberes, e à formação de profissionais cidadãos igualmente responsáveis. 
Dessa forma, a responsabilidade social universitária, sob o prisma da gestão, ganha contornos que incluem uma gama de ações e processos cujo objetivo é responder às demandas de seu ambiente de maneira adequada, formando um elo entre o conhecimento gerado dentro da universidade e as necessidades locais, perfazendo uma nova postura de gestão sob esse prisma. Nessa ótica, Macedo (2004) apregoa que a gestão assume uma nova dinâmica, que vai além da tradicional administração de patrimônio e de atividades acadêmicas, suscitando um perfil democrático que fortalece a gestão social e politicamente democrática.

Dentro dessa visão, Calderón (2006) ensina que existe uma estreita relação entre as práticas acadêmicas (Ensino, Pesquisa e Extensão) e as práticas gerenciais (conjunto de processos e estruturas gerenciais que permitem às universidades cumprir sua missão institucional), as quais deveriam estimular os princípios e valores verificados na base da responsabilidade social universitária. Esses elementos, para Pernalete e Ortega (2010), indicam a possibilidade de criação de uma simbiose entre universidade e sociedade, permitindo um elo que valorize todos os atores envolvidos nesse processo, da universidade à sociedade.

Considerando esse cenário, a compreensão da responsabilidade social universitária sob o olhar teórico, permite refinar a reflexão sobre a universidade no que tange à sua estrutura funcional, ao direcionamento das atividades acadêmicas e à sua forma de governança. Calderón (2006, p. 8) destaca que:

\begin{abstract}
Se, por um lado, o entendimento da responsabilidade social universitária que se tinha há mais de quatro décadas ainda mantém vigência, podemos afirmar que ele tem adquirido novos matizes em decorrência das rápidas mudanças ocorridas no mundo, em termos políticos, econômicos, culturais, informacionais decorrentes da crise do estado de bem-estar, da hegemonia do neoliberalismo, da aceleração do processo de globalização econômica, do surgimento da sociedade global de informação e do conhecimento e, principalmente, do fim da guerra fria.
\end{abstract}

Nessa linha, Carrizo (2006) argumenta que as universidades devem se transformar em um instrumento acelerador do processo de transformação social, atribuindo a si mesmas a missão de ditar o ritmo da história, visão compartilhada também por Florestan Fernandes (1975). A responsabilidade social para as universidades deve considerar as 
auguras de um mundo complexo, de diferenças sociais e desigualdades de oportunidades. Por essas argumentações, ganha destaque a visão de responsabilidade social associada diretamente ao desenvolvimento humano, condição compartilhada por Wagenberg (2006), Kliksberg (2006), Vallaeys (2006), Carrizo (2006) e Morin (2002). Especificamente, Morin (2002) acrescenta que o desenvolvimento sob o viés unicamente econômico provoca a prevalência da pobreza material e da alma dos socialmente excluídos; ainda, destaca a necessidade do diálogo permanente entre os processos técnicos e econômicos, aliados a preceitos éticos de solidariedade e de responsabilidade.

Sob essa vertente, Santos (1995) enfatiza que os pressupostos da responsabilidade social devem atender a critérios além da vertente econômica, estimulando a ótica da orientação social e política diante de problemas sociais. O autor destaca que o desafio está no alinhamento entre a sustentabilidade institucional, sob o ponto de vista econômico, e os indicativos de responsabilidade social universitária que valoriza o bem-estar social e a vida humana como finalidade absoluta.

Nessa ótica, Vallaeys (2006) defende uma nova dinâmica universitária, permeando três fatores: a garantia da responsabilidade social da ciência, a promoção da formação cidadã democrática e a formação calcada nos fundamentos da formação transversal de agentes para o desenvolvimento. Esse viés formativo deve ser disseminado por meio do ensino, da pesquisa e da extensão, elementos tradicionais e basilares das universidades que, segundo Vallaeys (2006, p. 45), permitem a "construção das pontes entre a universidade e a sociedade, a concretização do compromisso social da universidade e a reflexão ética sobre a dimensão social do ensino e da pesquisa, e têm sido uma atribuição da chamada extensão universitária".

Considerando essa perspectiva, Calderón (2006) e Vallaeys (2006) compartilham que a responsabilidade social universitária carece de uma visão mais abrangente e sistêmica, considerando as diversas partes da instituição em um projeto de promoção social com princípios éticos, sustentáveis, justos e de desenvolvimento social, sustentando o processo de ensino e aprendizagem para a transmissão de saberes com vistas à formação de cidadãos também responsáveis socialmente. Nessa perspectiva, Jimenez de La Jara et al. (2006) destacam que a responsabilidade social universitária é a: 
[...] capacidade que possui a universidade de difundir e colocar em prática um conjunto de princípios e valores, gerais e específicos, por meio de quatro processos considerados chaves: gestão, docência, pesquisa e extensão universitária, respondendo socialmente desta forma perante a própria comunidade universitária e o país onde está inserida.

A visão de Jimenez de La Jara et al. (2006) coaduna-se com as perspectivas anteriores, Calderón (2000, 2003, 2004, 2005, 2006), Wagenberg (2006), Kliksberg (2006), Vallaeys (2006), Carrizo (2006) e acrescenta um componente fundamental para a execução da responsabilidade social, que os autores chamam de elemento-chave, que é a gestão, contribuição que deve se consolidar a partir da definição de mecanismos administrativos que viabilizem a responsabilidade social nas universidades. Verifica-se, portanto, que passa necessariamente pela postura e pelo modelo de governança das universidades, o desejo executivo de direcionar as atividades institucionais - Ensino, Pesquisa e Extensão -, aliadas à postura de gestão para atender ao pressuposto transversal da responsabilidade social nas ações e nos processos de interação com a sociedade.

A responsabilidade social universitária carece de estratégias claras para a sua execução, conforme aborda Vallaeys (2006), que sugere quatro linhas de ação institucionais para a sua efetivação:

1) Gestão interna: transformar a universidade em uma comunidade ética, socialmente exemplar, democrática e transparente econômica e politicamente, com viés no desenvolvimento sustentável;

2) Docência: direcionar a aprendizagem baseada em projetos sociais, como enfoque multi e interdisciplinar, dado seu direcionamento na aprendizagem articulada com a Pesquisa, o Ensino e a Extensão;

3) Pesquisa: fomento a projetos com fins de desenvolvimento social, utilizando estratégias integradas com a comunidade tendo como viés a resolução de problemas locais;

4) Projetos sociais: proceder a uma interface entre cursos, departamentos, pesquisadores e estudantes engajados em projetos que se tornem fonte de pesquisa aplicada de recursos didáticos para a comunidade universitária. 


\section{Responsabilidade social universitária a partir da indissociabilidade}

A responsabilidade social universitária a partir da indissociabilidade resultou de processos sociais, ao longo das décadas, que a incluíram como um requisito para as instituições serem consideradas universidades (MOITA; ANDRADE, 2009). Este princípio, a indissociabilidade entre ensino, pesquisa e extensão é apontado como referência do padrão de qualidade acadêmica para as instituições de ensino superior do país (CADERNOS DA ANDES, 1982). Trata-se de um movimento iniciado a partir de uma emenda apresentada pelo Fórum Nacional de Educação na Constituinte à Assembleia Nacional Constituinte, que propunha a indissociabilidade entre ensino, pesquisa e extensão como um novo paradigma para a universidade brasileira e foi incorporada à Constituição Federal de 1988 em seu artigo 207, que estabelece: “As universidades gozam de autonomia didático-científica, administrativa e de gestão e obedecerão ao princípio da indissociabilidade entre ensino, pesquisa e extensão" (BRASIL, 1988).

Nesse sentido, Pucci (1991) destaca que o conceito de indissociabilidade entre ensino, pesquisa e extensão, se apresenta como referência para a organização do trabalho pedagógico, embora de difícil concretização em face das condições políticas e estruturais da educação superior, e tornou-se premissa para pensar e propor alternativas para esse nível de ensino, incorporando-se como elemento de expressão dos movimentos acadêmicos, científicos e culturais. Trata-se de um movimento consagrado na Constituição Federal de 1988, fato que eleva a expressão indissociabilidade entre ensino, pesquisa e extensão como caminho elementar para a construção de uma universidade de bom nível acadêmico, com autonomia científica, democrática, independente, que se coloca a serviço da sociedade voltada para a formação cidadã da população brasileira (PUCCl, 1991).

Nessa ótica, a extensão universitária é uma das funções que compõe os pilares da instituição universidade, entretanto, tem sido alvo de críticas e proposições, cortejada por diversos setores da sociedade, assumindo ao longo dos anos diferentes concepções teóricas e ideológicas, que influenciam na própria concepção de universidade. As análises dos discursos dos estudiosos do tema apresentam abordagens teóricas que fundamentam a extensão como função social da Universidade, ainda, no contexto da globalização, abertura de mercado e privatização das instituições públicas, impondo uma 
nova abordagem teórica e prática à extensão universitária, a mercadológica (JEZINE, 2004).

Por outro norte, Rays (2002) apresenta a extensão universitária sob a acepção crítica, visto ser um processo que vai até a sociedade, aos diversos segmentos sociais, a fim de estender os produtos do ensino e da pesquisa gerados no âmbito acadêmico. Nesse sentindo, a extensão universitária caracteriza-se como um processo que traz para a universidade tanto os problemas, quanto os conhecimentos gerados nos mais variados segmentos da sociedade, argumentos compartilhados por Jezine (2004), Rays (2002), Moita e Andrade (2009).

Por esse olhar, a responsabilidade social universitária se vale das atividades de extensão como uma alternativa para consolidar seus princípios, o que, segundo Vallayes (2006, p. 39),

[...] exige, a partir de uma visão holística, a articulação dos diversos setores da instituição, em um projeto de promoção social de princípios éticos e de desenvolvimento social equitativo e sustentável, com vistas à produção e transmissão responsáveis de saberes, e à formação de profissionais cidadãos igualmente responsáveis.

Adicionalmente, é necessário que as IES adotem uma atitude ética e socialmente responsável em todas as suas atividades perante a sociedade, assumindo de fato o seu papel diante das inúmeras demandas sociais.

\section{Considerações finais}

Pontualmente, a responsabilidade social trata do cumprimento dos deveres e obrigações dos indivíduos e empresas com a sociedade, assim, as instituições responsáveis socialmente devem integrar-se à comunidade, procurando contribuir de forma ética para sua melhoria. A transversalidade que a mesma permite aos principais envolvidos discentes, docentes, funcionários e comunidade atendida, oportuniza o aprimoramento da atitude científica, pois no exercício da atividade extensionista é possível integrar teoria e prática, consideradas imprescindíveis experiências para o processo formativo. 
Quando colocamos em pauta o tema responsabilidade social, imediatamente reconhecemos algumas vertentes de atuação, aplicação de recursos financeiros em projetos sociais, programas de qualidade de vida, sustentabilidade de comunidades localizadas em regiões desprovidas de recursos, entre outros, mas seu conceito é abrangente, definido como o compromisso que uma organização deve ter com a sociedade, por meio de atos e atitudes que a afetem positivamente, de forma ampla e especifica, agindo proativamente no que tange seu papel com a sociedade e a sua prestação de contas para com ela.

Nessa linha, Torres (2012) destaca que a responsabilidade social "faz com que se pense globalmente, a sociedade está cada vez mais entrelaçada e conectada entre si, fazendo com que as ações locais repercutam de uma forma mais impactante e transformadora de valores". Assim, é possível considerar que a prática da responsabilidade social universitária traz benefícios não somente ao público-alvo de suas ações, mas à própria universidade, pela criação de vínculo de identidade e lealdade com os destinatários.

Nesse sentindo, é possível notar que a responsabilidade social das universidades se caracteriza como um elo entre o conhecimento gerado institucionalmente e os impactos na sociedade em termos de desenvolvimento, chamando a atenção para a importância de um alinhamento entre os conhecimentos gerados pelas universidades, o que elas desenvolvem quando da sua inserção nos mais diversos ambientes e a efetiva utilização desses conhecimentos pela sociedade, de forma que estejam coerentes com os propósitos previstos na missão institucional.

A verificação desses elementos é feita por meio do processo de avaliação do ensino superior (SINAES) que está diretamente relacionado com a necessidade de adaptação da educação às exigências de qualidade, o que tem levado à busca de novas estratégias de gestão educacional. Ainda que existam resistências quanto ao processo de avaliação, é necessário compreender que avaliar significa agregar valores, por isso a importância do respeito à identidade do que está sendo avaliado, sendo que as universidades empenham esforços para implantar programas de avaliação institucional (interna), a fim de obter subsídios que favoreçam ações administrativas e acadêmicas que levem ao alcance da qualidade do ensino. 
Nesse contexto, é notório que toda atividade de avaliação encontrará inevitavelmente barreiras, obstáculos a transpor e apresenta alguns desafios como individualismo dos profissionais, repetição rotineira das práticas, tempo que se tem ou que se necessita para a realização dessa atividade, desmotivação dos protagonistas, desconhecimento, desinformação e falta de recursos orçamentários. Porém, apesar das dificuldades, há de se considerar a prudência, a ousadia e a determinação como imprescindíveis para o sucesso da avaliação institucional.

O processo avaliativo impacta inevitavelmente na qualidade da educação, visto seu enfoque da eficiência, isso aparece quando se propõem sistemas de indicadores para o ensino superior, ideia defendida por Ferrer (1999), que ainda afirma que uma instituição será eficiente se seus recursos e processos forem utilizados apropriadamente e cumprirem sua função, ou seja, existe a preocupação com o uso adequado dos recursos e o desenvolvimento dos processos quanto aos resultados alcançados.

Por este olhar, é necessário alimentar a reflexão qualitativa da educação, visto que a responsabilidade social implica, entre outros elementos, a capacidade da universidade em consolidar nos estudantes consciência crítica e compreensão abrangente do mundo, permitindo que por meio do desenvolvimento de uma visão sistêmica, se torne objeto e resultado de uma sociedade mais justa e democrática.

Necessariamente, a qualidade da educação universitária passa pela capacidade dos instrumentos avaliativos em medir adequadamente os efeitos da sua prática, e pela forma como são acompanhados os resultados dos mesmos, bem como pelas ações e pela cultura de responsabilidade social que a universidade imprime em toda a comunidade acadêmica.

Percebe-se que a responsabilidade social na universidade não se dá de forma tradicional, mas por meio de projetos de extensão como está determinado no artigo 207 da Constituição Federal de 1988. Entretanto, para que alguma ação na universidade seja instituída como extensão, é necessário que se tenha uma política de extensão que traga conceitos, diretrizes, além das finalidades e funções abordadas em instâncias institucionais deliberativas e normatizadas por meio de estatutos, regimentos, plano de desenvolvimento institucional, resoluções, portarias e editais, sendo que a consolidação 
da responsabilidade social nas universidades está associada direta e indiretamente à sua missão, focada na necessidade interdisciplinar e multidisciplinar das relações.

Evidencia-se, portanto, que as universidades, ao estimularem projetos de extensão, resultantes do esforço da pesquisa e discussão formativa no ensino, cumprem e operacionalizam seu papel institucional de indissociabilidade entre o ensino, pesquisa e extensão, princípio reforçado por Moita e Andrade (2009); Cadernos da Andes (1982); Pucci (1991); Raye (2003).

A partir dessas perspectivas, consolida-se a emergência social de soluções a problemas prementes das pessoas, induzindo um comportamento das universidades para que sejam vanguardas nesse processo, assumindo a responsabilidade social em seus processos de ensino, pesquisa e extensão, comprometendo-se por meio da sua missão, com os reflexos perversos de uma sociedade de grandes desigualdades, sendo capaz de suportar, em certa medida, os excluídos pela pobreza, pela fome, pela falta de segurança, pelas enfermidades e pela falta de garantias de seus direitos sociais. Para tal feito, se apresenta necessária a incorporação de preceitos éticos alinhados à realidade social, suportando o ensino, a pesquisa e a extensão universitária, enraizando culturalmente essas práxis indissociável de todo o processo de ensino, pesquisa e extensão.

Evidencia-se, portanto, que a educação de qualidade passa, entre outros elementos, pela consolidação da RSU, para tal feito é necessário o olhar atento da gestão aos princípios da indissociabilidade entre o ensino, pesquisa e extensão, elementos constitutivos e findos das universidades, que quando não executados adequadamente, contrariam e violam o preceito legal (CADERNO DA ANDES, 1982; PUCCI, 1991; MOITA; ANDRADE, 2009).

\section{Referências}

ALESSIO, Rosemeri. Responsabilidade social das empresas no Brasil: reprodução de postura ou novos rumos. Porto Alegre, EDIPUCRS, 2008.

CADERNOS DA ANDES. Proposta das AD's e da ANDES para a Universidade Brasileira. Juiz de Fora, n. 2, 1982. 
ASHLEY, Patrícia Almeida; FERREIRA, Roberto do Nascimento; REIS, Helvécio Luiz. Sistema Nacional de Avaliação da Educação Superior: oportunidades para a responsabilidade social na gestão estratégica de instituições de ensino superior. Revista Ibero-Americana de Estratégia, v. 5, n. 1, p. 23-35, 2006.

BRASIL. [Constituição (1988)]. Constituição da República Federativa do Brasil. Brasília, DF: Senado Federal, 1988.

BRASIL. Lei n 10.861, de 14 de abril de 2004. Institui o Sistema Nacional de Avaliação da Educação Superior - SINAES e dá outras providências. Diário Oficial da União, Brasília, DF, 15 abr. 2004a. Disponível em: < http://www.planalto.gov.br/ccivil_03/_Ato20042006/2004/Lei/L10.861.htm>. Acesso em: 06 set. 2017.

BRASIL. Ministério da Educação. Plano de Desenvolvimento da Educação. Brasília: Ministério da Educação, 2007.

BURLAMAQUI, Marcos Guilherme Bravo. Avaliação e qualidade na educação superior: tendências na literatura e algumas implicações para o sistema de avaliação brasileiro. Estudos em Avaliação Educacional, São Paulo, v. 19, n. 39, p. 133-153, jan./abr. 2008.

CALDERÓN, Adolfo Ignácio. Universidades mercantis: a institucionalização do mercado universitário em questão. São Paulo em Perspectiva, São Paulo, v. 14, n. 1, 2000.

CALDERÓN, Adolfo Ignácio. A universidade mercantil e o caso da universidade pública: reflexões a partir da experiência chilena. Eccos Revista Científica, São Paulo, v. 5, n. 1, 2003.

CALDERÓN, Adolfo Ignácio. Repensando o papel da universidade. RAE-Revista de Administração de Empresas, São Paulo, v. 44, n. 2, abr./jun. 2004.

CALDERÓN, Adolfo Ignácio. Responsabilidade social: desafios à gestão universitária. Estudos, Brasília-DF, ano 23, n. 34, p. 13-39, abr. 2005.

CALDERÓN, Adolfo Ignácio. Responsabilidade social universitária: contribuições para o fortalecimento do debate. Estudos: Revista Brasileira de Mantenedoras de Ensino Superior, Brasília-DF, ano 24, n. 36, p. 7-22, jun. 2006.

CARRIZO, Luís. Conhecimento e responsabilidade social: ameaças e desafios para a universidade transdisciplinar. Estudos, Brasília, DF, ano 24, n. 36, p. 76-89, mar. 2006.

CUNHA, Célio da; WERTHEIN, Jorge. Políticas de educação: ideias e ações. Brasília, UNESCO, 2004.

DRUCKER. O melhor de Peter Drucker: a administração. São Paulo: Nobel, 2009.

FERNANDES, Florestan. Universidade brasileira: reforma ou revolução. São Paulo: AlfaOmega, 1975. 
FERRER, Alejandro Tiana. La evaluación y la calidad: dos cuestiones sometidas a influência de determinados fatores no Exame Nacional de Cursos. Fundação Cesgranrio, Brasília, DF, v. 7, n. 22, p. 25-46, jan./mar. 1999.

INSTITUTO NACIONAL DE ESTUDOS E PESQUISAS EDUCACIONAIS ANÍSIO TEIXEIRA (INEP). Nota Técnica nº 14 /2014 - CGACGIES/DAES/INEP/MEC. Brasília, 2014. Disponível em:

<http://download.inep.gov.br/educacao_superior/avaliacao_institucional/nota_tecnica/20 14/nota_tecnica_n14_2014.pdf $>$. Acesso em: 3 out. 2015.

JEZINE, Edineide. As práticas curriculares e a extensão universitária. In: Congresso Brasileiro de Extensão Universitária, 2., 2004, Belo Horizonte. Anais... Belo Horizonte, 2004. Disponível em: <http://br.monografias.com/trabalhos-pdf901/as-practicascurriculares/as-practicas-curriculares.pdf>. Acesso em: 6 set. 2017.

JIMÉNEZ DE LA JARA, Mónica et al. Responsabilidade universitária: uma experiência inovadora na América Latina. Estudos, Brasília, DF, ano 24, n. 36, p. 57-73, mar. 2006.

KLIKSBERG, Bernardo. A ética e a responsabilidade social da universidade. Estudos: Revista da Associação Brasileira de Mantenedores de Ensino Superior, Brasília, DF, Ano 24, n. 36, p. 23-25, mar. 2006.

MACEDO, Lino de. Ensaios Pedagógicos: como construir uma escola para todos? Porto Alegre: Artmed, 2004.

MOITA, Filomena Maria Gonçalves da Silva Cordeiro; ANDRADE, Fernando Cézar Bezerra de. A indissociabilidade entre ensino, pesquisa e extensão: o caso do estágio de docência na pós-graduação. Revista Brasileira de Educação, v. 14 n. 41 p. 269-293, maio/ago. 2009. Disponível em:< http://www.scielo.br/pdf/rbedu/v14n41/v14n41a06.pdf>. Acesso em: 06 set. 2017.

MORIN, Edgar. Estamos em un Titanic? In: KLIKSBERG, Bernardo. Ética y desarrollo:la relación marginada. Buenos Aires: El Ateneo, p. 143-148, 2002.

PERNALETE, Mariela Torres; ORTEGA, Miriam Trápaga. Responsabilidad social de la universidad: retos y perspectivas. Buenos Aires: Paidós, 2010.

PUCCI, Bruno. A indissociabilidade entre Ensino Pesquisa e Extensão. Impulso, Piracicaba, p. 33-42, 1991.

RAYS, Oswaldo Alonso. Ensino pesquisa extensão: notas para pensar a indissociabilidade. Cadernos de Educação Especial, Santa Maria: Universidade Federal de Santa Maria, v. 1, n. 19, 2003. $114 \mathrm{p}$.

SANTOS, Boaventura de Sousa. Pela mão de Alice: o social e o político na pósmodernidade. São Paulo: Cortez Editora, 1995. 
TORRES, Luiz Eduardo Santos. Proposta de modelo de gestão universitária baseado em sustentabilidade: aplicação ao caso PUC-Rio. 2012. 67 f. Dissertação (Mestrado em Engenharia de Produção) - Pontifícia Universidade Católica do Rio De Janeiro, Rio de Janeiro, 2012.

UNESCO. Open file on inclusive education. Paris: [s.n.], 2003.

VALLAYES, F. Que significa responsabilidade social universitária? Estudos: Revista da Associação Brasileira de Mantenedores de Ensino Superior, Brasília, DF, Ano 24, n. 36, p.35-56, jun. 2006.

WAGENBERG, Alan. A urgência da responsabilidade social universitária. Estudos, Brasília, DF, ano 24, n. 36, p. 27-34, mar. 2006.

Universidade do Estado de Santa Catarina - UDESC

Programa de Pós-Graduação em Educação - PPGE

Revista Linhas

Volume 20 - Número 43 - Ano 2019

revistalinhas@gmail.com 